\title{
A Study of Cultural Translation from the Perspective of Cultural Fax
}

\author{
Yameng Zhang \\ Zhejiang Yuexiu University of Foreign Languages, Shaoxing, China \\ Email:229146776@qq.com
}

How to cite this paper: Zhang, Y.M. (2020) A Study of Cultural Translation from the Perspective of Cultural Fax. Open Access Library Journal, 7: e6450. https://doi.org/10.4236/oalib.1106450

Received: May 22, 2020

Accepted: June 7, 2020

Published: June 10, 2020

Copyright $\odot 2020$ by author(s) and Open Access Library Inc.

This work is licensed under the Creative Commons Attribution International License (CC BY 4.0).

http://creativecommons.org/licenses/by/4.0/

\begin{abstract}
Language is the carrier of culture. Translation is not only a shift between two languages, in fact, between two cultures. The process of collision and communication is the way of two different cultural exchanges and dialogues. Therefore, "cultural fax" should be the basic source of translation. The so-called cultural fax requires the target language to be culturally oriented and accurately reproduce the meaning, form and style that the original language is intended to convey. It is to convey the cultural connotation of the original language to the greatest extent. It is handed to the target readers so that they can fully understand the original culture. It can produce cultural feelings similar to the original readers so as to enrich the translation culture while exporting the original culture. However, it is not easy to achieve this goal in the process of translation. The paper mainly studies the theoretical basis of cultural translation through the analysis of the relationship among culture, language and translation. Cultural translation is explored through the study of different meanings of culture in a context. It mainly includes the analysis of the structure between culture and language, and the verification of the internal connection between culture and translation. Fax culture refers to the translation of basic standards, which requires the translation of the meaning, form and style of the text to be accurately expressed from the perspective of culture.
\end{abstract}

\section{Subject Areas}

Linguistics

\section{Keywords}

Cultural Translation, Cultural Fax, Cultural Context

\section{Introduction}

Language is a vehicle that interprets and records culture. Language is an impor- 
tant tool for human life and communication. It is indispensable to inherit and develop human civilization. It is also influenced by geographical areas, the long-term development of people living in different areas, so language is based on its own character. This requires that in addition to mastering the best English translation skills, the most important thing is to do it from a cultural perspective. Translation needs to maximize the accuracy as well as the meaning of both the Chinese and English content, especially from a practical point of view. It is necessary to analyze the application in detail. To some extent, language is the symbolic representation of a nation, which comprises its cultural backgrounds as well as ways of living and thinking. In the vast culture of Eastern and Western countries, culture translation reflects a nation's history, custom, religion, etc. Generally, it is also bonded with social activities, natural phenomena, some concrete instances and abstract concepts. Cultural exchange and cooperation between countries are increasing with the development of information age and the speeding up of globalization. In current decades, the world has been changed into a global village where people can't live without being influenced by others. Meanwhile, it brings misunderstanding and cultural shocks, which are all obstacles we should overcome in cross-cultural communication. Consequently, the necessity of intercultural communication becomes all the more obvious. Intercultural translation has aroused a widespread concern among scholars. Translation is not only carried out in two languages, but also inseparable from cultural factors, such as regions, religions, historical customs and nationalities, psychological awareness, etc.

\section{Overview of Cross-Cultural Perspective Transformation}

If we analyze it from the perspective of historical development and practice, the main reasons for the transformation of cross-cultural perspective come from the following aspects.

\subsection{Differences between Ethnic Cultures}

English translation itself has a certain complexity. It is not only the conversion between Chinese and English, but also the mutual conversion and exchange between the national cultures represented by the two languages. The translator must fully understand the differences between Chinese culture and the national culture of English, so as to ensure that the translation work is easy and improve the accuracy of translation. Because Chinese and English belong to different languages and have different cultural backgrounds, Chinese culture has the characteristics of multiple connotations. If analyzed from the nature of language, it is a specific character formed on the basis of understanding the image of things, focusing on the meaning of Chinese characters. English is different. It belongs to alphabetic writing. It uses abstract letters to express phonetic meaning [1].

\subsection{The Differences between National Life Style}

Due to the distance between different regions and the difference of surrounding 
environment, each nation has formed its own unique living habits and customs in the process of development. In ancient times, China's transportation is inconvenient, and a large part of its territory belongs to inland areas, so Chinese people are accustomed to inland life and have relatively less communication with foreign countries. However, the communication between western countries is closer and they are more open-minded. In addition, the surrounding areas are close to the sea and the shipping industry is developed, which also makes western countries more adventurous and free in character. These differences will also affect the translation between Chinese and English to a certain extent.

\subsection{The Difference of Thinking Mode of National Language}

The differences of two languages also exist in thinking and language logic. In a certain degree, it brings many difficulties to the translation work. First of all, Chinese attaches great importance to harmony and unity in language expression, while English thinking is the opposite, from individual to individual. Secondly, influenced by historical factors and ancient philosophical factors, Chinese expression pays more attention to the features of semantics and operation and maintenance, while English pays more attention to structural integrity. In terms of language interpretation, it emphasizes the true meaning represented by some specific language structures. Finally, Chinese is more logical in terms of language expression, which can achieve accurate expression of specific things; English is able to describe and express things through abstraction, not directly reflect things.

\section{The Importance of Intercultural Perspective in English Translation}

With the development of globalization, international cultural exchanges are becoming more and more frequent. In order to ensure more effective communication in culture, trade and politics, translation has gradually become a key work. English, as one of the most widely used languages in the world, is also the main language tool used in the communication between western countries, which requires English translators to fully understand the differences of different countries in the actual translating process, and to carry out translation work in combination with cultural background, history, living habits, thinking habits and other aspects so that the essence of the same culture can be accurately expressed in the process of translation, reducing the differences between the translated content and the original content. If the translation is based on the literal meaning, it may be contrary to the original content or has a large deviation, which will have a negative impact on the work [2]. This is a direct illustration of the importance of cross-cultural transformation in ensuring the accuracy of translation. Therefore, it is necessary for English translators to focus on the reality and consider from multiple levels to realize the relevant transformation between English and Chinese, so as to meet the current needs of China's foreign trade, political diplomacy, business and other special English occasions. 


\section{Cross Cultural Perspective Transformation and English Translation Skills in English Translation}

Based on the above analysis, it is necessary to change the cross-cultural perspective in English translation. The translator must integrate the cross-cultural perspective and English translation skills from the practical perspective, so as to express the meaning of English text more accurately.

\subsection{Personal Conversion}

Due to the influence of its own development factors, there are great differences between Chinese and English in terms of language expression, and even the opposite. This requires English translators to have a strong comprehensive quality, fully understand the culture and language habits of both Chinese and English, so as to ensure English translation to the greatest extent Accuracy. For example, in the process of subject expression, English is a way of expression with "things" as the main body, while in Chinese, the main body is often "people". In view of this situation, in the process of English translation, it is necessary to realize the conversion between people to ensure that the original meaning of the language will not deviate after translation [3]. Translators should fully master the planning translation skills, in order to make the text more in line with the reader's self-Body language habits, easy for readers to understand the relevant content. At the same time, in the western society, understanding is more important in daily life, so in the process of translating the text, we need to consider the content of etiquette, and change the order of person. For example, in the translation of the relevant sentences of responsibility recognition, the translator can put the first person before the other person to avoid misunderstandings and improper etiquette. In addition to the above problems, western countries do not make a more detailed division in terms of all kinds of kinship terms. When it is necessary to translate from Chinese to English, we should pay attention to combining the actual situation and make a preliminary division of the relationship between the characters, so that the conversion between people can be more reasonable and reduce the possibility of errors.

\subsection{Word Conversion}

In English, the same word often has many different meanings. In addition, the English expression is more willing to describe things abstractly. Therefore, in terms of words, the translator must analyze them as a whole, flexibly transform words and use them alternately according to the actual situation, so as to improve the accuracy of English translation and make the translated text conform to the actual situation. This paper analyzes the relationship between Chinese and western language habits, Chinese logical thinking and so on, so as to ensure that the translation quality can meet the expected requirements, and use some similar words to enhance the appeal of language expression and improve the translation effect. In addition, if there are verbs, nouns and prepositions in the process of 
translation, it is necessary to fully consider the context, scene and other aspects, combined with the characteristics of Chinese language, translate nouns into verbs, affirmative to negative and other skills, so that readers can further understand the meaning of the text. Take the translation of "no man choose evil because it is evil; he only misses it for happiness, the good he sees" as an example. After translation, the content of this passage is: a person goes to evil not because he yearns for evil, but mistakenly considers evil as the happiness he pursues. In this process, the translator realizes the reasonable conversion of negation and affirmation, which makes the translated text more suitable for people's reading needs, and makes the effectiveness of translation to the maximum extent.

\subsection{Statement Conversion}

Influenced by the differences of Chinese and Western culture, background, living environment, customs and so on, there are obvious differences between Chinese and English in sentence expression. In English, inversion and ellipsis are relatively frequent. They are more willing to put objects and other people in front of them. If they need to criticize, they are more willing to praise first, and then elaborate their own views. For this feature, the translator must fully understand it, and then combine the translation of the original content, transform it into a sentence pattern method that can be widely accepted by all aspects of the readers, and finally meet the readers' reading needs. In addition to this consideration, the translator should also take into account the actual situation of mood, context and other aspects to determine the translation content more accurately, so that the language statements can be presented to the readers in a clearer and smoother way. It should be noted that translators should pay attention to the differences between the translation of words and the translation of simple sentences. In the content of the article, there will be certain thoughts of the author, and these thoughts themselves have certain uniqueness. Therefore, in the process of translation, translators need to understand the thoughts and creative ideas that the author wants to express more deeply, and integrate their own imagination on the basis of understanding the general idea of the article, so as to achieve a deeper understanding of the content of the article. In order to ensure the translation effect, English translators need to further understand the cultural situation of the author's country, closely contact with culture, to analyze the original meaning of the author's writing, translate the content of the article into the most acceptable sentences, and ensure that the sentences, the artistic conception of the article, the connotation and so on can be preserved from the original.

\subsection{Foreignization Translation}

In the process of translation, English translators are likely to encounter a variety of different ways of expression, but also cannot directly translate the source language, which requires translators to express the relevant content in the most appropriate and equivalent meaning on the basis of the source language. Although they cannot achieve formal equivalence, they can make the content more com- 
prehensive and specific [4]. On the one hand, translators need to translate positive and negative words flexibly, on the other hand, they need to make full use of English by combining cultural similarities and differences.

Due to the strong flexibility of vocabulary, the translation content can be reasonably transformed, which makes the current sentence translation not smooth enough, or the sentence problem that cannot be directly translated can be reasonably and effectively solved, so as to improve the overall translation effect. For example, when translating the statement "smoking is not allowed in this theater", we can apply the passive voice, so as to improve the problem of sentence irregularity and ensure the smooth expression of the sentence.

\section{Definition of Cultural Translation and Cultural "Fax"}

Cultural "Fax" here means the basic principles of cultural translation. It requires the target language to accurately reproduce the meaning, mode and style of the original language from the perspective of cultural meaning. In other words, it embodies the "form" and "spirit" of the original language in the target language. It can be seen that the study of cultural "Fax" is a key part of translation. The reason why translation is not so easy is that language reflects culture, carries rich cultural connotation and is restricted by culture. Once using language to communicate, there are problems in understanding and expressing cultural connotation. This requires the translator not only to have bilingual ability, but also bicultural and even multi-cultural knowledge, especially to have a certain understanding of the national psychological awareness, cultural formation process, historical customs, traditions, religious culture and a series of regional features of the two languages. It is precisely these mutual factors that reflect the unique national character of the English and Chinese languages and cultures. For example, there is such a sentence in a dream of Red Mansions: "It's not like the granddaughter of the old ancestor, but the granddaughter of his own family. "It is generally believed that the consanguinity of a legitimate grandson or granddaughter should be related to the grandson or granddaughter. Wang Xifeng undoubtedly means that Lin Daiyu has an extraordinary temperament, just like the granddaughter of Jia $\mathrm{Mu}$, so as to win the favor of Jia $\mathrm{Mu}$. If we translate this sentence as "She doesn't take after your side of the family, grannie. She's more like a Jia." In this way, it may be derogatory to Jia Mu's family. Yang Kangli, who are familiar with the Chinese tradition, translate this sentence as "She doesn't take after her father, son-in-law of our old ancestress, but looks more like a Jia." The translation makes Fengjie's implication well expressed and faithfully conveys the traditional sense of Chinese feudal family to the readers.

The religious beliefs of English and Chinese are different, which will naturally be reflected in the language. The main culture in English is the Christian culture, the Bible, which plays an immeasurable role in the formation and development of Western civilization. Correspondingly, Buddhism culture has a profound influence in China. Both cultures have their own characteristics in thinking mode, language expression forms, lexical images and meanings, so we should pay spe- 
cial attention when we do translation. For example, Hawkes translated "Emituofou" in a dream of Red Mansions into "God bless my soul" and used God to replace the Buddha, which may make Westerners think that Chinese believe in God as well. Such kind of translation greatly reduces the connotation of Chinese culture. Another example is that the idiom of "Heaven takes the lead in killing the earth" uses "heaven" and "Earth" as the symbol of the highest power, but it can only be applied to China which is deeply influenced by the concept of heaven, so it cannot be replaced by "God", which reflects the Christian faith. The translation of some words with foreign feelings is also a difficult point. As for the translation of English idioms, there are a number of studies. It has been a long tradition in the researching of idioms. The relative studies can elevate people's language competence and communicative skills. Efforts are made to conclude some common properties and differences of idioms between English culture and Chinese culture, and elaborate further into the reasons which account for the differences. An intensive research on idioms employed in English and Chinese languages is in hope of better understanding the cultural connotations of idioms so as to make the cross-cultural communication more effective. In addition, offering a miniature of the impact on idioms exerted by culture, which can surely promote the communication between people from different cultures. So the research on translation between English and Chinese idioms from a cultural perspective is of great value and will benefit learners in further studies. In the future, more studies will serve to figure out such comparisons and analyses so as to encourage more cross-cultural communication. Translation of English and Chinese idioms has profound reference value to confer, hence the necessary of this research.

It can be seen from the above that the translation of "cultural translation" is indeed done in the context of "cultural research", and cultural "Fax" is the key to cultural translation.

\section{The Degree of Cultural "Fax" in Translation}

Cultural "Fax" not only refers to faithfulness of the original language, but also seek the best translation method under the premise of considering foreign culture. As for what is its "degree", there are no fixed rules to follow, so how to accurately grasp its scale remains to be honed and explored by translators for a long time. The paper intends to talk about his superficial understanding of the "degree" of bilingual transformation from the following three aspects.

\subsection{Explore the Historical, Social Background and Cultural Connotation of Words and Accurately Know the of Cultural "Fax"}

Cultural translation should not only consider the historical and social background, but also pay attention to those words with similarities and differences. Translators should keep clear thinking, pay attention to the deep cultural connotation, and understand the similarities and differences of the language. 
Get Rid of the National Psychological Restriction of Sexual Taboo and Sexual Repression

Sometimes it is difficult for the original text to be translated faithfully because of the similarities and differences of social customs and ethics of different nationalities. In France, for example, once men and women can kiss their lips, they can almost be together. So in order to be accustomed to the national habits and avoid damaging the image of the target country, the French changed the British paternity kiss to French paternity hug when translating English novels. Obviously, this is a rewriting that is different from the original meaning and cannot achieve the effect of "Fax".

\subsection{Don't Put on "Long Gown and Mandarin Jacket" to "Foreigners", and Reflect the Original Cultural "Fax"}

When talking about translation, Lu Xun especially stressed that we should pay attention to foreign sentiment, that is, the so-called Westernization. "Foreign spirit" here refers to the preservation of the foreign cultural features contained in the original language, so as not to bring the unique Chinese color to the English language. At the same time, we should avoid imposing the distinctive national or local color of Chinese into the translation.

For example, the English idiom (a region) "flowing with milk and honey" comes from the Bible. Milk and honey are familiar food for westerners. This idiom, for example, if translated into the Chinese "land of fish and rice", it is somewhat different, though its meaning is similar. Therefore, it is more appropriate to translate it into "a land of abundant resources". Another example: "when Greek meet Greek, then comes the tug of war", this proverb originates from the stubborn resistance of ancient Greek cities to the Macedonian King Philip and Alexander. Later it is often used to describe the fierce fighting scene when two warriors or two brave armies fight. Some people translate it as "Zhang Fei meets Zhang Fei and kills all over the world". In this sentence, Zhang Fei is a historical figure in China, and there is no such one in Britain, so it is not suitable to appear in the translation. It is more original to be translate as "When two heroes meet, their fight will be fierce".

\subsection{Appropriate Use of Idioms and Norms in Chinese and Best Way to Show Cultural "Fax"}

The process of cultural translation practice can be said to be the process of deeply analyzing the original language and cultural content, gaining its meaning, realizing its spirit, and then expressing it with the tempered translation language. Not only does the target language maintain the original flavor, but it also needs "local flavor" when necessary, that is, adopting the standard Chinese and the customary expression accepted by the Chinese, otherwise it will not be able to achieve the "Fax" effect.

\section{Cultural Differences Reflected in Idioms}

In a narrow sense, culture is equal to the intellectual and conceptual culture. In 
contrast, culture means human culture in a broad sense. Culture is an extremely complex concept and an enormous subject. It consists of both material things and non-material things, such as schools, cities, organizations, as well as customs, languages, ideas and individual values.

\subsection{Significance of Cultural Factors in Idiom Translation}

As a symbolic communication system, human language is infinitely flexible and includes a variety of components. Idiom is more typical to reflect a culture compared with other language ingredients. Eugene A. Nida [5] once claimed that "for truly successful translating, biculturalism is even more important than bilingualism, since words only have meanings in terms of the cultures in which they function." Over the recent decades, as the culture studies deepening, scholars have been dwelling on the relationship between translation and culture and made constant achievements in various aspects. The inseparable relationship between culture and language is sure to exert great influence on translation. Whether the cultural values are same or not, they will certainly leave traces on the corresponding languages' translation. Similarly, translation is an effective way to transfer them to a certain cultural background as well as absorb the cultural essences of foreign countries. Translation serves as a method of cultural inter-mediation. The more and more frequent and convenient communication has contributed to the vitally important role of translation. It has been a long time since culture and translation have been linked to each other in literary works. Ideas or thoughts should be selected, oriented, and combined in idiom translation. Each culture places its own constraints on the translation process. Idiom, as one of the lexical components, has specific grammatical structure, meaning and usage. It has been considered as a particular genre in linguistic studies so far, in which they apply numerous theories to translation. Needless to say, it closely ties to distinctive cultural factors and cultural values. Idioms are the most culturally loaded element, for they record all the details or trace of the culture. That is to say, idioms can give clear reflection of different cultures. Therefore, the cultural factors reflected in idioms have great values to consult in the process of linguistic transfer. It is necessary for a successful translation to Master the translation of idioms from a cultural perspective.

\subsection{Cultural Factors within Idioms}

\subsubsection{Customs}

Custom involves all sorts of aspects of social life. Everyone, from cradle to grave, behavior, his feeling, and experience are affected by customs. Idioms are featured in profound life flavor and distinctive national color. Customs are the reflections of a nation's cultural consciousness in the fast development of the society. A great number of idioms are derived from habits or customs. The cultural differences relating to customs between English and Chinese are presented in many aspects. The most typical one lies in men' attitude towards animals. $\mathrm{Hu}-$ man beings advocate peaceful co-existence with animals. In China there are 
many dog-related idioms and the word "dog" in most phrases is associated with some derogatory connotation, but it is always considered as the most faithful human friend in English custom. Vast majority of such expressions in English are complimentary.

\subsubsection{Religions}

Religion is a sort of spiritual phenomenon and an important composing part of culture. It reflects different attitudes towards each nation's taboo and admiration. Since English and Chinese nationalities have different religious beliefs, they also have differences in terms of the word connotations. The sharply different religious idioms are the best representations of the two nations' religious concept. Chinese people believe in Confucianism, Buddhism, and Taoism, while English people believe in Christianity. In traditional Chinese culture, there are "Emperor" and "Dragon king" in myths and fables. In contrast, God is the cultural image of Englishmen. They believe that God created and arranged the whole world. A famous English saying "Man proposes, God disposes" reflects the great influence of Christianity. Likewise, Buddhism is a major source from which idioms relating with religions derive. A typical example of Chinese idiom "to present Buddha with borrowed flowers" reflects the Chinese worship of Buddha and religious belief.

\subsubsection{Historical Allusions}

Both China and Britain have their long-standing languages. Historical allusions are an important cultural factor to influence the formation and development of idioms. To some extent, it expresses the concept of culture in a comprehensive way. The cultural differences caused by historical allusions present a vivid picture of the nations. The emergence of idioms is associated with the labor and life of people. China is located in Eastern Asia, the west coast of Pacific Ocean. Its agriculture is cultivated well. While Britain is an island country and it used to be rich in fishery, ship manufacturing industry and marine transportation. On account of these distinct differences, people in two countries have different attitudes towards the same object. The idioms formed by historical allusions always have relatively simple patterns but profound meanings. In English history, there are two major sources to affect the origins of idioms. That is Rome Conquest and Shakespeare's excellent works, for instance, "A Herculean task", which means a task which requires great efforts of the body or mind. It is widely accepted that not all idioms have relative equivalents in another language. As a result, many idioms can only be translated from a cultural perspective according to its in-depth meanings.

\subsubsection{Lexical Vacancy and Culture Gap}

Lexical Vacancy refers to an absence of a word in a particular language. There exists extensively the phenomenon of lexical vacancy between target language and source language in translation. Often a concept lexicalized in one language does not have a corresponding lexical unit in another language. The vacancy in 
vocabulary mainly exists in its pragmatic and referential meaning. Many experts think that some idioms have gained special connotations and embodied intense national characteristics during the development of the countries. For instances, in the eyes of Chinese, silkworms are willing to sacrifice and don't make effort to contribute without requiring any pay back. A culture gap is any systematic difference between two cultures which hinders relations and mutual understanding. Culture gaps can relate to ethnicity, religion, age, or social class. Similarly, panda is the national treasure of China, which implies harmony and peace. Giant pandas are regarded as cultural exchanges in "Panda Diplomacy" to express good wishes. As one of precious species, panda is peculiar to China, and it's for this reason that it has cultural meanings in China.

\subsubsection{Native Flavor Expression}

Let's take a proverb as an example: the man is the black sheep of family. If we translate this proverb into "that man is the black sheep of the whole family", we will feel puzzled and wonder what it means. There are two mistakes in the translation: one is that the image in the Chinese people's mind is not clear; the other is that the similarities are not pointed out. If the underlined part is replaced by the "black horse", the meaning of the metaphor will be clear at a glance.

The mutual reference of languages can enrich the expressiveness of the two languages. Many words with strong foreign flavor have been integrated into Chinese. From the perspective of English, Westerners are also willing to collect some foreign expressions they don't have. For example, "like two cocks in the same cage" can be translated into English directly, which can be accepted by British and American readers. If you add another one "you'll see the flying feathers" in English, the Chinese meaning is "sure to fight with blood till the feathers fly", then it will be more vivid. Another example, "It is better to draw the pond in order to get all the fish" and "to kill the goose that lays the golden eggs". Though it seems to have lost a little "foreign flavor" for the first sentence, it can embody the local flavor of the idiom with strong Chinese characteristics.

The four character structure of Chinese integrates all kinds of language elements and means of expression. It has strict structure and rich implication. If it can be used properly in the translation, it will get a rare rhetorical effect.

\section{Conclusion}

We must consider three elements: national cultural, tradition cultural content and cultural psychology of different regions in order to accurately grasp the degree of cultural "Fax" in translation. On the macro level, the translator should understand the implication of culture, the basic theory and skills of translation, and on the micro level, he should carefully observe the differences among the above three elements and make a comparison and analysis, so as to find out the causes of "cultural distortion". In a word, only by integrating "faithfulness, expressiveness and elegance" under the premise of considering foreign cultures, can we do translation appropriately, so as to ensure the realization of cultural 
"Fax" and really do cultural translation well.

\section{Conflicts of Interest}

The author declares no conflicts of interest regarding the publication of this paper.

\section{References}

[1] Wu, Q. (2017) On the Transformation of Cross-Cultural Perspective and Translation Skills in English Translation. Intelligence, 27, 229-230.

[2] Pan, R.B. (2018) An Analysis of Cross-Cultural Perspective Transformation and Translation Skills in English Translation. Research on Labor Security, 1, 88-90.

[3] Fan, Y.H. (2016) A Study of the Cross-Cultural Perspective Transformation and Translation Skills in English Translation. Journal of Heilongjiang Institute of Education, 7, 118-120.

[4] He, Y.H. (2014) An Analysis of Cross-Cultural Perspective Transformation and Translation Skills in English Translation. Modern Communication, 12, 24-26.

[5] Nida, E.A. (1993) Language, Culture and Translating. Shanghai Foreign Language Education Press, Shanghai. 